\title{
A Study of the Mental Wellbeing of Imprisoned Women in Iran
}

\author{
Jalal Khademi \\ Åbo Akademi University, Vasa, Finland \\ Kaj Björkqvist \\ Åbo Akademi University, Vasa, Finland \\ Karin Österman \\ Åbo Akademi University, Vasa, Finland
}

\begin{abstract}
The study investigates the social functioning and mental well-being in 35 women prisoners (mean age $=28.7$, $S D=7.6$ ) on death row in the Gorgan jail, northeastern Iran. Most of them had received their sentence for killing their husband. A control sample of 35 women of the same age from Gorgan was included. The respondents filled in a paper-and-pencil questionnaire. The women on death row scored higher than the controls on aggression, anxiety, and hostility; the controls scored higher than the women on death row on social support and emotional self-efficacy. The women on death row had, to a greater extent than the controls, a family history with addiction problems and suicidality.
\end{abstract}

Keywords: death row, women, prison, well-being, social functioning, Iran

\section{Introduction}

The present study has its focus on women on death row in Iran. Studies on the mental health of prisoners who have received the capital punishment are scarce; studies of women on death row are even more so. At least in western societies, women are under-represented on death row: Strieb (2001) found that only $2.8 \%$ of the individuals executed in the United States since 1608 have been females. Women are under-represented on death row even in comparison with how often they commit murder. Strieb (ibid.) reports that women account for $13 \%$ of murder arrests, but only $1.9 \%$ of death sentences.

In a review article, Cunningham and Vigen (2002), summarize that rates of psychological disorders among death row inmates in general are high. Several studies have found evidence of psychosis (Freedman \& Hemenway, 2000: Lewis, 1979: Lewis, Pincus, Bard, Richardson, Prichep, Feldman, \& Yeager, 1988; Lewis, Pincus, Feldman, Jackson, \& Bard, 1986; Cunningham \& Vigen, 1999), paranoia (Panton, 1976, 1978) depression (Cunningham \& Vigen, 1999; Freedman \& Hemenway, 2000; Gallermore \& Panton, 1972; Johnson, 1979); and PTSD (Freedman \& Hemenway, 2000). Head injuries and neurological impairements are also common (Lewis et al., 1986). Many death row inmates have a history of trauma, family disruption, and substance abuse (Cunningham \& Vigen, 2002).

Women who kill differ from men in the sense that they more often than men - in more than $50 \%$ of the cases - kill someone from their own family, most often their husband (Clevenger \& Roe-Sepowitz, 2009; Snell, 2001). Women who kill, but who do not have an abusive husband to blame for their outburst, or a postpartum psychosis to explain the homicide of their baby, are to the world-at-large a strange and alien group, since they do not fit in with the usual gender stereotypes. The reaction to female offenders is expressed in the "evil woman hypothesis", i.e. the view that women who offend outside normative gender roles are to a double extent deviant (Gavin \& Porter, 2015).

But are they? It has long been known that women conduct as much intimate partner violence - at least low intensity violence - as men, and that the majority of violent intimate relationships are mutually violent (Straus \& Gelles, 1985; Stets \& Straus, 1990). This view has been referred to as symmetry theory (Archer, in press). In support of this view, some recent studies (Australian Bureau of Statistics, 2012; Kar \& O'Leary, 2010) have found women to be just as likely as men to be violent. 
However, an examination of criminal records shows that intimate partner violence leading to severe injury or homicide more often is directed from men against women than vice versa (Grech \& Burgess, 2011). This finding provides support for the gender asymmetry theory, the traditionally held view.

Archer (in press) therefore suggested a revised symmetry theory, suggesting that as far as low intensity aggression is concerned, gender symmetry holds, but when the level of violence increases to the level of the infliction of physical injury and homicide, men are perpetrators to a greater extent than women. This theory unifies the two approaches, and it is to our understanding the most accurate conceptualization of the issue so far.

While the most severe cases of intimate partner violence with a deadly outcome are directed against women, more than $40 \%$ of cases of severe physical violence in the U.S. still are directed at men (National Intimate Partner and Sexual Violence Survey, 2010).

In 2016, 526 individuals were executed in Iran (Amnesty International, 2017). Not all of these death penalties were due to homicide, however. There is to date no available data about how common it is in Iran that women commit homicide in comparison with men. Neither do we know in how many of these cases they react against violence they themselves have been exposed to from abusive husbands, and whether they act in self-defense. What we do know is that women in Iran who kill their husbands more or less without exception are sentenced to death. Whether they will be executed or not is up to the relatives of the deceased husband; they have the power to pardon the woman on death row, often in exchange for a sum of money. However, even in the case of being pardoned, the women will have to spend between 3 to 10 years in prison.

\section{Method}

\section{Sample}

The total sample consisted of 70 women, including 35 imprisoned women on death row and 35 women who served as a control group. The imprisoned women were all from Gorgan prison; Gorgan is a city in northeastern Iran. All of them had been sentenced to death, in most cases for killing their husband. The women in the control group were all from the city of Gorgan, free and with no history of criminal charges. They were randomly selected in order to match the imprisoned group with regard to age, education, and marital status. The women of the samples were all from an age range of 18-40 years of age. The mean age of the women on death row was 28.7 years $(S D=7.6)$, and the mean age of the women of the control group was 29.1 years $(S D=5.3)$. The age difference was not significant.

\section{Instrument}

The data were collected by use of a questionnaire. The questionnaire consisted of seven scales and some single items. (1) Aggression was measured with the Mini Direct and Indirect Aggression Inventory (Mini-DIA; Österman \& Björkqvist, 2010); (2) victimization from others' aggression was measured with the victim version of the Mini-DIA (ibid.); (3) emotional self-efficacy was measured with the emotionality subscale of the Self efficacy Questionnaire (SEQ; Muris, 2001); (4) social support was measured with the Multidimensional Scale of Perceived Social Support Assessment (MSPSSA; Zimet, Dahlem, Zimet, \& Farley, 1988). Three subscales from the Brief Symptom Inventory (BSI; Derogatis, 1975) were also included in the test battery: (5) depression, (6) hostility, and (7) anxiety. The number items of each scale, as well as Cronbach's a-values as a measure of reliability, are presented in Table 1.

In addition, there were questions pertaining to whether there had been histories of addiction problems and suicide in the family. However, these were not scales but nominal level single items, which were analysed separately.

Table 1: The Scales of the Study, Number of Items and Reliability (Internal Consistency) Scores Measured with Cronbach's a.

\begin{tabular}{lll}
\hline Scales & Number of items & Reliability \\
\hline Aggression & 4 & .74 \\
Victimisation & 5 & .84 \\
Hostility (BSI) & 5 & .83 \\
& & \\
Depression (BSI) & 6 & .89 \\
\hline
\end{tabular}




\begin{tabular}{lll}
\hline Anxiety (BSI) & 6 & .94 \\
Social Support & 8 & .74 \\
\hline
\end{tabular}

\section{Procedure}

The data were gathered on site in the prison with one of the researchers present. It took about one hour to fill in the questionnaire. For the collection of data from the control group, the same questionnaire and procedure were used.

\section{Ethical considerations}

The data were collected under strict anonymity with the informed consent of jail authorities and, above all, the women themselves. The study adheres to the principles concerning human research ethics of the Declaration of Helsinki (World Medical Association, 2013), as well as guidelines for the responsible conduct of research of The Finnish Advisory Board on Research Integrity (2012).

\section{Results}

A multivariate analysis of variance (MANOVA) was conducted with group belonging (women on death row vs. controls), as independent variable, and the seven scales (Aggression, Victimization, Hostility, Depression, Anxiety, Social support, Emotional Self-efficacy) as dependent variables. The results are presented in Table 2 and Figure 1.

As can be seen, the women on death row scored significantly higher on Aggression, Victimisation, Hostility, and Anxiety; there was a tendency towards a significant difference on Depression. They scored significantly lower than the controls on Social Support and Emotional Self-efficacy.

The women on death row had, more often than the controls, a family history with addiction problems $(74.3 \%$ of the cases vs. $37.1 \%$ of the cases among the controls; $\left.X^{2}(1)=9.79, p=.002\right)$ and suicide $(37.1 \%$ of the cases vs. $14.3 \%$ among the controls, $X^{2}(1)=4.79, p=.029$ ).

Table 2: Results from a Multivariate Analysis of Variance (MANOVA) with Group Belonging (Women on Death Row vs. Controls) as Independent Variable and the Seven Scales of the Study as Dependent Variables (cf. Fig. 1).

\begin{tabular}{llllll}
\hline & $\mathrm{F}$ & $\mathrm{df}$ & $\mathrm{p} \leq$ & $\eta_{\mathrm{p}}{ }^{2}$ & $\begin{array}{l}\text { Group } \\
\text { differences }\end{array}$ \\
\hline Multivariate Analysis & 8.09 & 8,68 & .001 & .515 & \\
Univariate Analyses & & & & & \\
$\quad$ Aggression & 10.09 & 1,68 & .002 & .130 & $\mathrm{DR}^{*}>\mathrm{C}^{* *}$ \\
$\quad$ Victimisation & 0.09 &, & $\mathrm{~ns}$ & .001 & \\
$\quad$ Hostility (BSI) & 9.95 &, & .002 & .129 & $\mathrm{DR}>\mathrm{C}$ \\
Depression (BSI) & 3.12 &, & .085 & .044 & $(\mathrm{DR}>\mathrm{C})$ \\
Anxiety (BSI) & 21.06 &, & .001 & .237 & $\mathrm{DR}>\mathrm{C}$ \\
Social Support & 14.97 &, & .001 & .182 & $\mathrm{C}>\mathrm{DR}$ \\
$\quad$ Emotional Self Efficacy & 8.93 &, & .004 & .116 & $\mathrm{C}>\mathrm{DR}$ \\
\hline
\end{tabular}

Note: ${ }^{*} \mathrm{DR}=$ Women on Death Row; ${ }^{* *} \mathrm{C}=$ Controls

\section{Discussion}

The findings corroborate previous findings about the mental status among prisoners on death row (cf. the review by Cunningham and Vigen, 2002). The women in this study scored significantly higher than the controls on aggression, hostility, and anxiety, and there was a tendency towards a significant difference on depression. It should be noted that also in regard to depression, the effect size $\left(\eta_{p}^{2}\right)$ was .044; due to the small sample size, however, the group difference did not fully reach significance. In regard to social functioning, the women on death row scored lower than the controls on emotional self-efficacy and social support. 
The results thus provide a similar picture of the mental health and social functioning of individuals on death row in Iran with that of death row inmates in for instance U.S.A.

The study is unique in two respects. It is, to our knowledge, the first study in the world to focus solely on women inmates on death row. Second, we do not know of any previous study that has investigated the well-being of death row inmates in Iran.

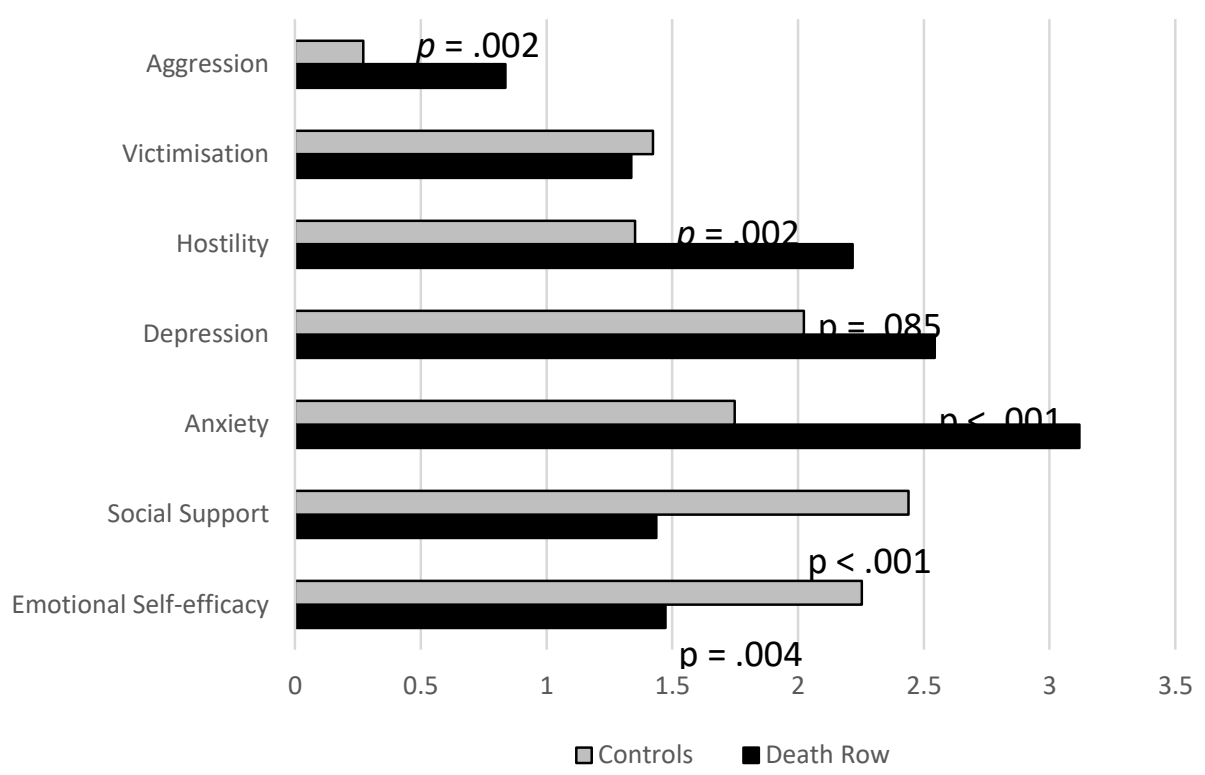

Figure 1. Mean scores for women on death row and controls on the seven scales of study (cf. Table 2).

\section{References}

[1] Amnesty International (2017). Death sentences and executions in 2016. URL: http://www.amnesty.org/en/documents/act50/5740/2017/en/

[2] Archer, J. (in press). Violence to partners: gender symmetry revisited. In J. L. Ireland, P. Birch, \& C. A. Ireland (Eds.), International handbook on aggression. New York: Routledge.

[3] [Australian Bureau of Statistics (2012). Crime victimisation, Australia, 2010-11, cat. no. 4530.0. Canberra: Australian Bureau of Statistics.

[4] Clevenger, B. J. M., \& Roe-Sepowitz, D. (2009). Shelter service utilization of domestic violence victims, Journal of Human Behavior in the Social Environment, 19, 359-374.

[5] Cunningham, M. D., \& Vigen, M. P. (1999). Without appointed counsel in capital postconviction proceedings: The self-representation competency of Mississippi death row inmates. Criminal Justice and Behavior, 26, 293321.

[6] Cunningham, M. D., \& Vigen, M. P. (2002). Death row inmate characteristics, adjustment, and confinement: A critical review of the literature. Behavioral Sciences and the Law, 20,191-210.

[7] Derogatis, L. R. (1975). Brief Symptom Inventory. Baltimore, MS: Clinical Psychometric Research.

[8] Finnish Advisory Board on Research Integrity (2012). Responsible conduct of research and procedures for handling allegations of misconduct in Finland. Helsinki: Finnish Advisory Board on Research Integrity.

[9] Freedman, D., \& Hemenway, D. (2000). Precursors of lethal violence: A death row sample. Social Science \& Medicine, 50, 1757-1770. 
[10] Gallemore, J. L., \& Panton, M. A. (1972). Inmate responses to lengthy death row confinement. American Journal of Psychiatry, 129, 167-172.

[11] Gavin, H., \& Porter, T. (2015). Female aggression. Chichester, UK: Wiley \& Blackwell.

[12] Grech, G., \& Burgess, M. (2011). Trends and patterns in domestic violence assaults: 2001 to 2010. New South Wales Bureau of Crime Statistics and Research, No. 61. URL: www.bocsar.nsw.gov.au/Documents/BB/bb61.pdf

[13] Johnson, R. (1979). Under sentence of death: The psychology of death row confinement. Law and Psychology Review, 5, 141-192.

[14] Kar, H. L. \& O'Leary, K. D. (2010). Gender symmetry or asymmetry in intimate partner victimization? not an either/or answer. Partner Abuse, 1, 152-168. doi.org/10.1891/1946-6560.1.2.152

[15] Lewis, P. W. (1979). Killing the killers: A post-Furman profile of Florida's condemned. Crime and Delinquency, $25,200-218$.

[16] Lewis, D. O., Pincus, J. H., Bard, B., Richardson, E., Prichep, L. S., Feldman, M., \& Yeager, C. (1988). Neuropsychiatric, psychoeducational, and family characteristics of 14 juveniles condemned to death in the United States. American Journal of Psychiatry, 145, 584-589.

[17] Lewis, D. O., Pincus, J. H., Feldman, M., Jackson, L., \& Bard, B. (1986). Psychiatric, neurological, and psychoeducational characteristics of 15 death row inmates in the United States. American Journal of Psychiatry, $143,838-845$.

[18] Muris, P. (2001). A brief questionnaire for measuring self-efficacy in youths. Journal of Psychopathology and Behavioral Assessment, 23, 145-149.

[19] National Intimate Partner and Sexual Violence Survey (2010). Summary report. URL: https://www.cdc.gov/violenceprevention/pdf/nisvs_report2010-a.pdf

[20] Österman, K., \& Björkqvist, K. (2010). The Mini Direct Indirect Aggression Inventory (Mini-DIA). In K. Österman (Ed.). Indirect and direct aggression (pp. 103-111). Frankfurt am Main: Peter Lang.

[21] Panton, J. H. (1976). Personality characteristics of death-row prison inmates. Journal of Clinical Psychology, 32, 306-309.

[22] Panton, J. H. (1978). Pre- and post-personality test responses of prison inmates who have had their death sentences commuted to life imprisonment. Research Communications in Psychology, Psychiatry and Behavior, 3, 143-156.

[23] Snell, T. L. (2001). Capital punishment 2000. Washington, DC: U.S. Government Printing Office.

[24] Stets, J. E., \& Straus, M. A. (1990). Gender differences in reporting marital violence and its medical and psychological consequences. In M. A Straus \& R. J. Gelles (Eds), Physical violence in American families: Risk factors and adaptions to violence (pp. 151-165). New Brunswick, NJ: Transaction Press.

[25] Straus, M. A., \& Gelles, R. J. (1985). Is family violence increasing? A comparison of the 1975 and 1985 National Survey rates. San Diego, CA: American Society of Criminology.

[26] Streib, V. L. (2001). Death penalty for female offenders: January 1, 1973, to December 31, 2000. URL: http://www.law.onu.edu/faculty/strieb/femdeath.htm

[27] Zimet, G. D., Dahlem, N. W. Zimet, S. G., \& Farley, G. K. (1988). The Multidimensional Scale of Perceived Social Support. Journal of Personality Assessment, 52, 30-41.

[28] World Medical Association (2013). Declaration of Helsinki: Ethical principles for medical research involving human subjects. JAMA, 310, 2191-2194. URL: https://www.wma.net/policies-post/wma-declaration-of-helsinkiethical-principles-for-medical-research-involving-human-subjects/ 